ORNL/TM-2018-828

CRADA/NFE-16-06318

Revision 1

\title{
Hybrid Multi-Material Endoskeleton Overmolded Structure for Automotive Powertrain
}

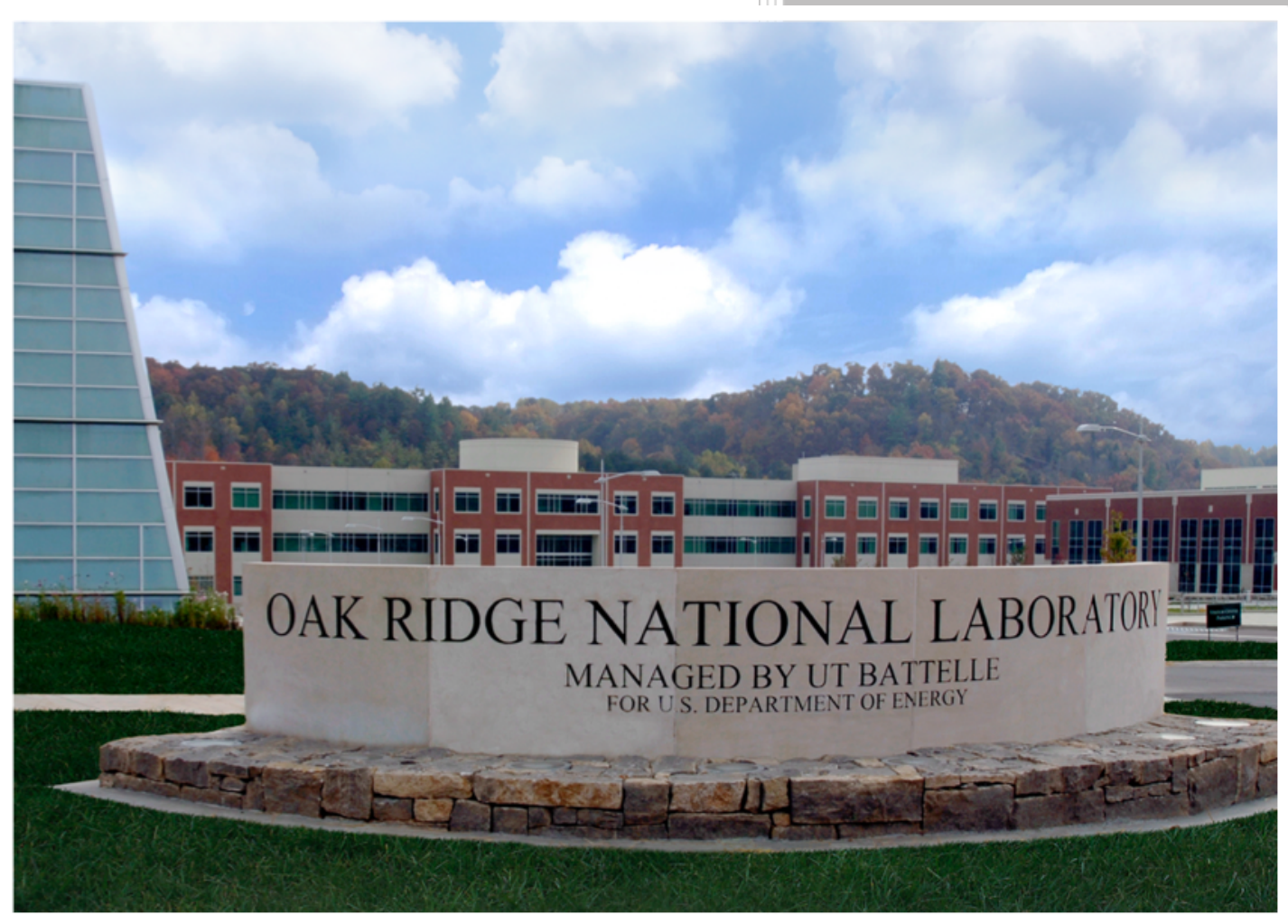

\section{CRADA final report for CRADA number NFE-16-06318}

Approved for public release. Distribution is unlimited.
William Peter Lonnie Love Phillip Chesser Katherine Gaul June 10, 2018 


\section{DOCUMENT AVAILABILITY}

Reports produced after January 1, 1996, are generally available free via US Department of Energy (DOE) SciTech Connect.

Website http://www.osti.gov/scitech/

Reports produced before January 1, 1996, may be purchased by members of the public from the following source:

National Technical Information Service
5285 Port Royal Road
Springfield, VA 22161
Telephone 703-605-6000 (1-800-553-6847)
TDD 703-487-4639
Fax 703-605-6900
E-mail info@ntis.gov
Website http://www.ntis.gov/help/ordermethods.aspx

Reports are available to DOE employees, DOE contractors, Energy Technology Data Exchange representatives, and International Nuclear Information System representatives from the following source:

Office of Scientific and Technical Information

PO Box 62

Oak Ridge, TN 37831

Telephone 865-576-8401

Fax 865-576-5728

E-mail reports@osti.gov

Website http://www.osti.gov/contact.html

This report was prepared as an account of work sponsored by an agency of the United States Government. Neither the United States Government nor any agency thereof, nor any of their employees, makes any warranty, express or implied, or assumes any legal liability or responsibility for the accuracy, completeness, or usefulness of any information, apparatus, product, or process disclosed, or represents that its use would not infringe privately owned rights. Reference herein to any specific commercial product, process, or service by trade name, trademark, manufacturer, or otherwise, does not necessarily constitute or imply its endorsement, recommendation, or favoring by the United States Government or any agency thereof. The views and opinions of authors expressed herein do not necessarily state or reflect those of the United States Government or any agency thereof. 
ORNL/TM-2018-828

CRADA/NFE-16-06318

Revision 1

Energy and Transportation Sciences

Advanced Manufacturing Office

\title{
HYBRID MULTI-MATERIAL ENDOSKELETON OVERMOLDED STRUCTURE FOR AUTOMOTIVE POWERTRAIN
}

\author{
William Peter \\ Lonnie Love \\ Phillip Chesser \\ Katherine Gaul
}

Date Published:

April 13, 2018

\footnotetext{
Prepared by

OAK RIDGE NATIONAL LABORATORY

Oak Ridge, Tennessee 37831-6283

managed by

UT-BATTELLE, LLC

for the

US DEPARTMENT OF ENERGY

under contract DE-AC05-00OR22725
}

Approved For Public Release 


\section{CONTENTS}

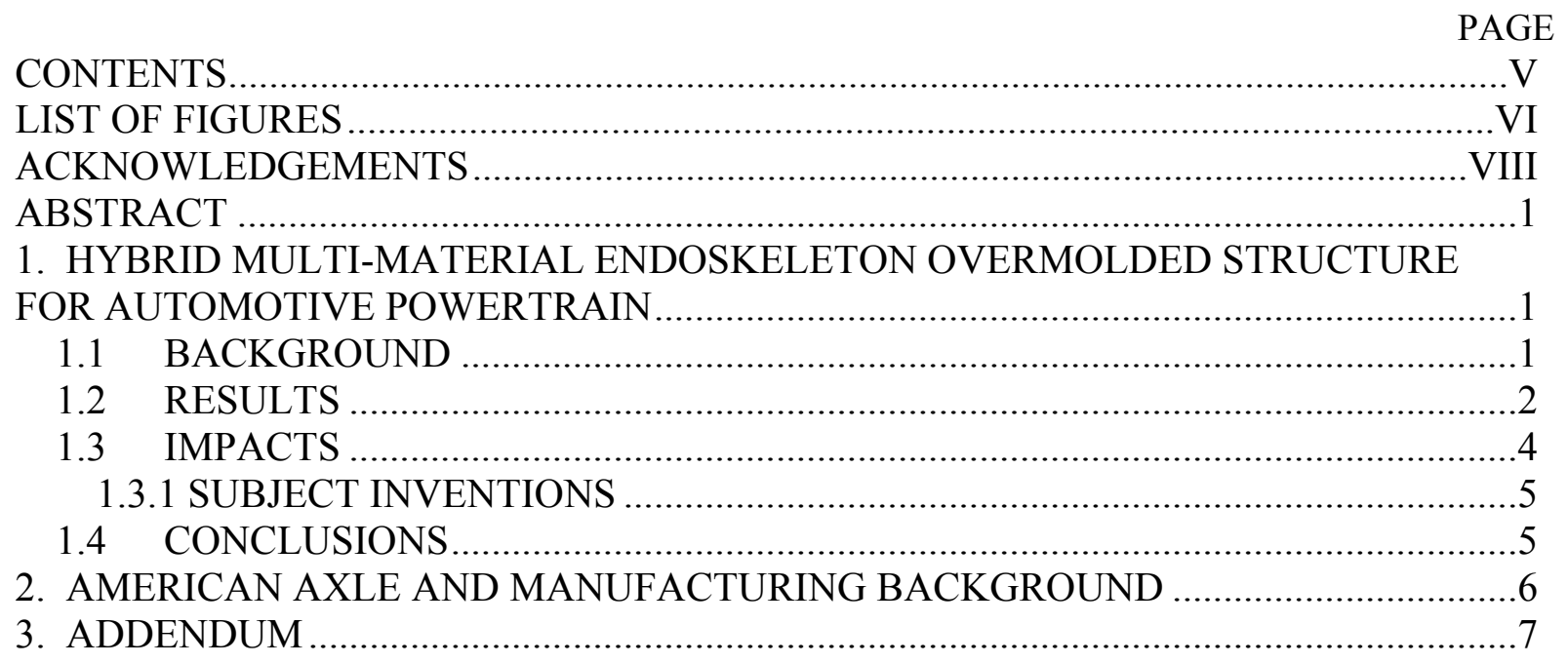




\section{LIST OF FIGURES}

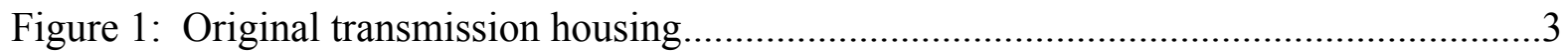

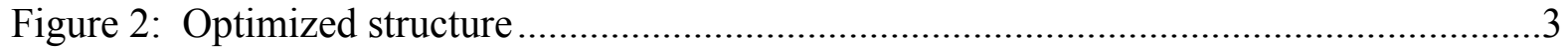

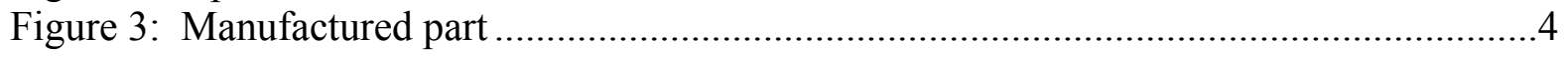

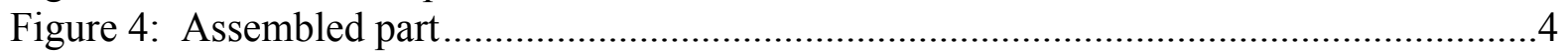




\section{ACKNOWLEDGEMENTS}

This CRADA NFE-16-06318 was conducted as a Technical Collaboration project within the Oak Ridge National Laboratory (ORNL) Manufacturing Demonstration Facility (MDF) sponsored by the US Department of Energy Advanced Manufacturing Office (CPS Agreement Number 24761).

Opportunities for MDF technical collaborations are listed in the announcement "Manufacturing Demonstration Facility Technology Collaborations for US Manufacturers in Advanced Manufacturing and Materials Technologies" posted at http://web.ornl.gov/sci/manufacturing/docs/FBO-ORNL-MDF-2013-2.pdf. The goal of technical collaborations is to engage industry partners to participate in short-term, collaborative projects within the Manufacturing Demonstration Facility (MDF) to assess applicability and of new energy efficient manufacturing technologies. Research sponsored by the U.S. Department of Energy, Office of Energy Efficiency and Renewable Energy, Advanced Manufacturing Office, under contract DE-AC0500OR22725 with UT-Battelle, LLC.

The team would like to acknowledge Jonarron Jones and his company, Volunteer Aerospace, for their work using the Concept Laser powder-bed system to manufacture prototype parts necessary for this project. 



\begin{abstract}
Oak Ridge National Laboratory's (ORNL) Manufacturing Demonstration Facility (MDF) worked with American Axle and Manufacturing (AAM) to demonstrate additive manufacturing's (AM) applicability to multi-material endoskeleton driveline mechanisms. The goal of this technical collaboration project was to significantly reduce mass, improve efficiency, and improve power torque density of the driveline mechanism through applied research analysis of a multi-material solution. The focus of the effort explored the impact of multi-material endoskeleton components on reducing the weight of a typical drivetrain component using a blend of metal additive manufacturing with overmolding. For this study, a conventional rear driveline power transfer unit housing was selected. The component was geometrically optimized for additive manufacturing and to ensure proper lubrication of the gears. Therefore, traditional weight reduction techniques were invalid because AM enables weight reduction far beyond what is capable with traditional manufacturing. The hypothesis was that an inner aluminum structure could be optimized with respect to strength and weight reduction. An outer composite surface was overmolded to the aluminum AM part to satisfy the part's geometric constraints and to provide embodiment for oil encapsulation. The original component weighed $11.3 \mathrm{lb}$ whereas the topologically optimized structure was $6.96 \mathrm{lbs}$, which is a $4.34 \mathrm{lb}$ difference. When the missing aluminum material was replaced with a composite material, the part weighed approximately $8.66 \mathrm{lbs}$ resulting in a $2.64 \mathrm{lb}$ or $23 \%$ weight reduction from the traditionally manufactured part. These efforts have been deemed a success. A proposed second phase will explore the material and design requirements necessary to ensure a viable mechanical interface between the AM component and overmolding.
\end{abstract}

\title{
1. HYBRID MULTI-MATERIAL ENDOSKELETON OVERMOLDED STRUCTURE FOR AUTOMOTIVE POWERTRAIN
}

This technical collaboration project (MDF-TC-23016-103) began on August 17, 2016 and was completed on April 13, 2018. The collaboration partner, American Axle and Manufacturing (AAM), is a large business with more than 1,000 employees. This project focused on optimization for reduced mass of a typical drivetrain component by means of an endoskeleton structure that met functional dynamic and static load requirements to enable driveline torque transfer. This report describes the results of the efforts focused on proof-of-principle manufacturing and resulting impact (weight reduction) possible through a hybrid approach using AM metallic, load-bearing structures and overmolding the remaining surfaces for lubricant control.

\subsection{BACKGROUND}

AAM currently uses cast iron and cast aluminum-based structures that require significant secondary subtractive machining, post thermal processing, and sealing to achieve the required adaptation features, structural integrity, and fluid encapsulation with regard to traditional powertrain torque transfer mechanisms. The current manufacturing processes and base materials that are used are constrained by traditional manufacturing limitations that inhibit further mass optimization. These traditional manufacturing limitations are directly attributable to efficiency losses, and therefore, impact the industry's ability to meet future CO2 legislative mandates. AAM seeks to gain an applied understanding of improving manufacturing process cycle times, the scalability of AM, and the applied use of multi-material engineered composites in an overmolded design concept. This comprehensive analytical study will foster AAM's readiness to support US-based technology in an applied effort to 
advance manufacturing processes, reduce mass, and improve efficiencies through hybrid endoskeleton powertrain applications.

The resulting multi-material endoskeleton overmolded structure for an automotive powertrain holds significant impact to advance AAM's technology development in numerous facets. The project enabled valuable insight in understanding the merits of AM in process, design optimization, materials characterization, and the aligned synergies by joining of dissimilar materials in both mechanical and molecular adhesion. The project scope supported key insights to understanding the value of eliminating traditional manufacturing and design constraints that support mass reduction with the potential to achieve up to $40 \%$ reduced mass as well as the elimination of post-secondary subtractive manufacturing and thermo mechanical processes that will improve material strength, material yield, reduce manufacturing energy consumption, improve process efficiencies, and reduce overall manufacturing costs. Further, value was realized through applied integration of lubrication passageways for optimization of thermal energy transfer by means of novel integrated circuitry. Uses of applied development hold potential for both mechanical and electric driveline architectures, with macro improvements in the reduction of the overall design envelope and improved thermal management through novel state of art approach in applied application. Ancillary considerations of embedded sensory for thermal management and intelligent structure could also be aligned in the study of this concept. The project scope offered numerous benefits to meet key industry and legislative greenhouse gas targets. AAM foresees continued adoption of scalability with the multi-material technologies because they demonstrated AM's costs performance improvements. These AM techniques are now being realized in composite-based materials for applied high volume automotive original equipment manufacturer (OEM) and tier-based manufacturing.

The approach for the chosen part focused on topology optimization for reduced mass by means of an endoskeleton structure that will meet functional dynamic and static load requirements to enable driveline torque transfer. The aluminum endoskeleton structure was constructed by means of a laser powder bed system (Concept Laser) that enabled unique topology optimization. Future efforts will focus on non-asymmetrical lattice structure to incorporate integration of primary lubrication passages, bearing retainers, and seal interface retainers that otherwise could not be manufactured with traditional subtractive manufacturing processes.

\subsection{RESULTS}

AAM used topology optimization to reduce the mass of an existing driveline power transfer unit housing. Through optimization, the part was reduced to $6.96 \mathrm{lbs}$. However, the housing body surfaces factor into the efficiency of transferring lubricants to the gears. Therefore, the hypothesis of this project was that AM could be used to manufacture an aluminum endoskeleton that could be overmolded with a lightweight polymer composite material to satisfy surface design constraints. The original transmission housing is shown in Figure 1. The overall mass of the structure is $11.3 \mathrm{lbs}$. 


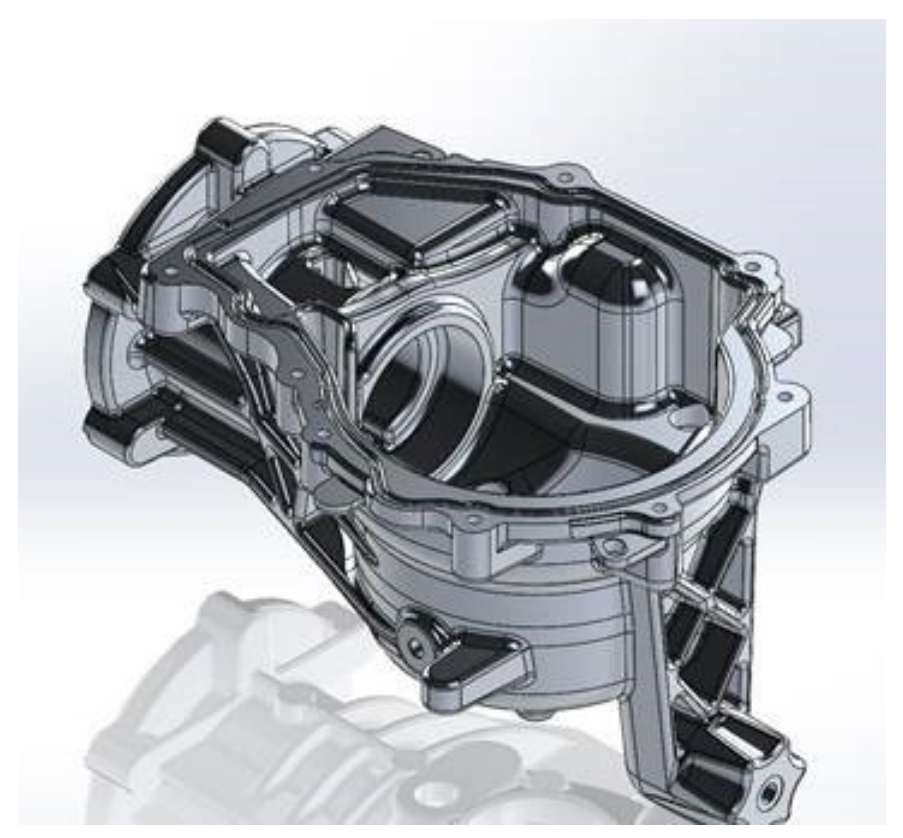

Figure 1: Original transmission housing design.

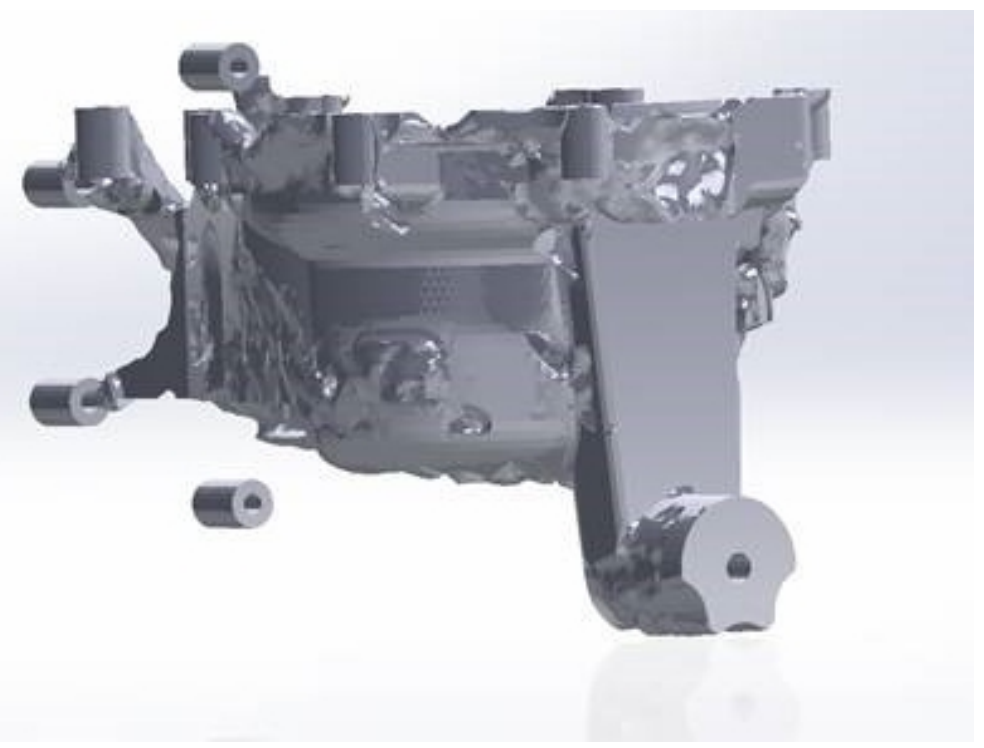

Figure 2: Optimized transmission housing design.

ORNL and AAM used Plato, a topology optimization software package, to minimize the part's weight as a function of design load constraints (see Figure 2). The mass of the part was reduced to $6.94 \mathrm{lbs}$, which is a $4.34 \mathrm{lb}$ weight reduction. If the missing aluminum is replaced with composite overmolding, the final part weight would be approximately $8.66 \mathrm{lbs}$, resulting in a $2.64 \mathrm{lb}$ overall weight reduction of $23 \%$. A prototype part was manufactured using a Concept Laser powder bed system (see Figure 3 and Figure 4). 




Figure 3: Prototype part manufactured using a Concept Laser laser powder bed system.

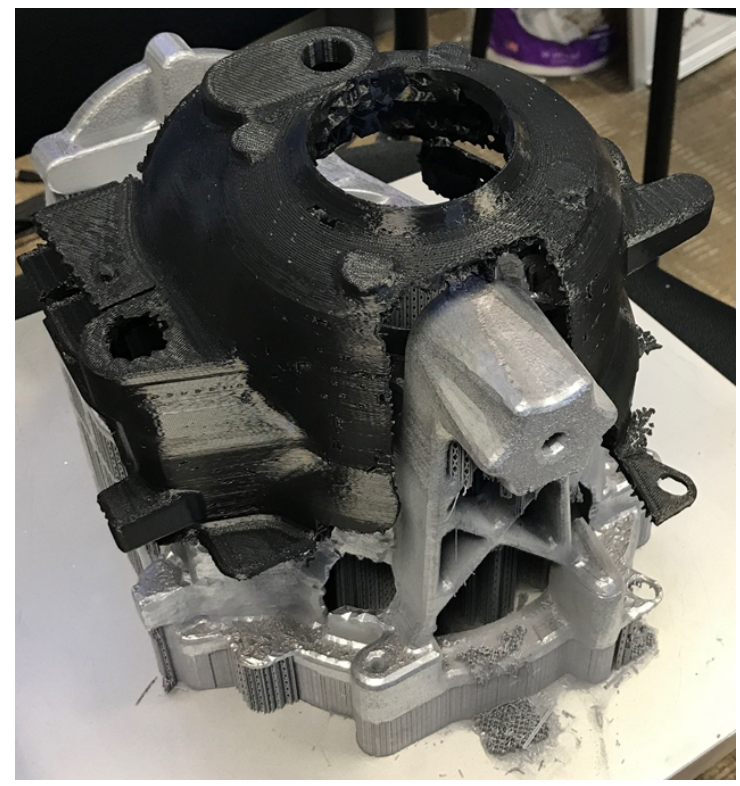

Figure 4: Assembled hybrid multi-material endoskeleton overmolded transmission housing design.

Efforts focused only on the impact AM and composite overmolding could have on weight reduction. Proposed follow on efforts will explore the integration of lattice structures for controlling interface integrity between the aluminum AM component and the composite overmolding.

\subsection{IMPACTS}

This project enabled valuable insight into understanding the merits of AM in process, design optimization, materials characterization, and the aligned synergies by joining dissimilar material in both mechanical and molecular adhesion. This project showed the value of eliminating traditional manufacturing and design constraints, while supporting mass reduction with the potential to achieve up to $23 \%$ reduced mass. The project provides one approach to manufacturing that could help 
industry meet key legislative GHG targets. This project creates opportunities for continued adoption and scalability of the multi-material technologies given the demonstrated acceleration of high speed additive manufacturing. Cost and performance improvements are also being realized in composite based materials for applied high volume automotive OEM and tier-based manufacturing.

\subsubsection{Subject Inventions}

There are no subject inventions associated with this CRADA.

\subsection{CONCLUSIONS}

The goal of the project was to demonstrate an ability to reduce the mass of an automotive part through the development of multi-material endoskeleton overmolded structures. This effort focused on a prototype driveline power transfer unit housing. The project demonstrated a $23 \%$ weight reduction through combined topology optimization with additive manufacturing and composite overmolding. Proposed follow on efforts will focus on developing interface geometries between additive parts and key nodal interfaces of lattice-based geometries that will provide structural contact and retention by means of composite overmolding that will enable high integrity mechanical interfaces between dissimilar materials. 


\section{AMERICAN AXLE AND MANUFACTURING BACKGROUND}

AAM is a global manufacturer of driveline and powertrain systems for the automotive, commercial and industrial markets. AAM specializes in the design, engineering, validation and manufacturing of driveline, metal forming, powertrain, and casting technologies. AAM has over 25,000 associates operating at more than 90 facilities in 17 countries to support their customers on global and regional platforms with a focus on quality, operational excellence, and technology leadership.

AAM's global footprint includes more than 90 locations across four continents (North America, South America, Asia and Europe). AAM is a global resource that brings driveline, powertrain, metal forming and casting products, $\&$ technologies to markets around the world helping to reduce the cost of vehicle-development programs. 


\section{ADDENDUM}

This report covers the efforts of a phase one cooperative research and development agreement. Phase 2 will be pursued with the industry partner under a separate cooperative research and development agreement with a non-federal entity number because the agreement the work above was performed under has expired. Therefore, this is a final report. 